\title{
A REINVENÇÃO DA SEXUALIDADE MASCULINA NA PARAPLEGIA ADQUIRIDA
}

\author{
Luiz Carlos Avelino da Silva ${ }^{\star}$ \\ Paulo Albertini ${ }^{\star \star}$
}

\begin{abstract}
Resumo
Neste trabalho a sexualidade masculina é discutida a partir da condição de um homem com lesão medular. Seu objetivo foi investigar o impacto da paraplegia adquirida na sexualidade masculina. Metodologicamente adotou-se uma abordagem qualitativa e coletou-se a história de vida por meio de entrevistas. As principais conclusões apontam para um deslocamento das representações da masculinidade associadas à força, virilidade e violência, para um posicionamento interno e a busca de formas de viver a sexualidade que valorizam a singularidade da experiência, em detrimento dos modelos tradicionais.
\end{abstract}

Palavras-chave: Deficiência fisica. Sexualidade masculina. Gênero. Violência.

\section{THE REINVENTION OF THE MALE SEXUALITY IN ACQUIRED PARAPLEGIA}

\begin{abstract}
In this work, the masculine sexuality is put into discussion taking in consideration the condition of a man with a medullar lesion. Its objective is to investigate the impact of the acquired paraplegia in the masculine sexuality. The methodological orientation adopted was the qualitative approach and the life story was obtained by means of interviews. The main conclusions indicate a displacement of the representations of masculinity - related to the strength, virility and violence - to a more interior positioning and to the seek of ways of living the sexuality that value the singularity of experiences, rather than the traditional models.
\end{abstract}

Keywords: Physical disability. Masculine sexuality. Gender. Violence.

* Professor Adjunto do Instituto de Psicologia da Universidade Federal de Uberlândia. Endereço: Rua Dr. Luiz Antônio Waack, 1050, Uberlândia - MG - CEP: 38402-030.

E-mail: luizavelino@yahoo.com.br


Getúlio, 506, apto 81-A, Aclimação, São Paulo - SP - CEP: 01509-000.

E-mail: albertin@usp.br 
As lesões medulares acometem mundialmente 30 pessoas por milhão de habitantes, principalmente homens na faixa etária entre 20 e 30 anos, segundo apontamentos de Casalis (1995). Na cidade de São Paulo, revela o estudo de Colucci (2003), a causa principal é a violência, por meio das armas de fogo e do trânsito.

Sob a perspectiva biomédica, o aspecto primário das deficiências, observa-se a existência de um dano ou anormalidade de estrutura ou função do corpo, que passa a apresentar alguma incapacidade. No caso específico do foco deste estudo, as paraplegias resultam de lesões (traumáticas ou não) "que comprometem os segmentos medulares localizados abaixo da T1 (primeiro segmento medular torácico), resultando em perda total dos movimentos e sensibilidade dos membros inferiores" (SCHERB, 1998, p. 27). Como seqüelas tendem a ocorrer perdas relacionadas à autonomia nas excreções, nas funções sexuais (compreendidas como os aspectos biofisiológicos da sexualidade, tais como ereções, ejaculações e fertilidade) e nos movimentos abaixo do local da lesão, além do aparecimento das úlceras de decúbito, presentes na maioria dos paraplégicos nos primeiros anos após o acidente.

O corpo dos paraplégicos, na região abaixo da lesão, é insensível à estimulação táctil, o que coloca algumas questões complexas diante do desejo sexual que persiste apesar das seqüelas. Por um lado aponta para a amputação (há um perda real, e não simbólica como na castração) de uma parte da sexualidade (a genital), pois não há regiões excitáveis, passíveis de serem erógenas. Por outro, indica um caráter exclusivamente representacional para a sexualidade.

$\mathrm{Na}$ esfera das seqüelas psicológicas, com os aportes de Vash (1988), nos deparamos com a impossibilidade de falar em uma personalidade ou mesmo psicologia típica das pessoas com deficiência. Mais especificamente sobre as deficiências adquiridas, Moor (1973) destaca dois aspectos: o primeiro diz respeito ao momento de sua instalação, que pode impedir ou frustrar projetos típicos da idade que se vive; o segundo coloca a questão de para quem se é pessoa com deficiência, se para os outros ou para si mesmo, assinalando que diferente de uma deficiência congênita, em que o indivíduo cresce e se desenvolve lidando com seus efeitos, as pessoas com deficiências adquiridas podem comparar-se consigo mesmo em dois momentos distintos, gerando sentimentos de menos valia.

Assim, além dos problemas orgânicos decorrentes da deficiência agrega-se outro: o impacto que a sua aquisição tem na subjetividade de seu possuidor. Alguns relatos, escritos pelas próprias pessoas com deficiência, no caso deficiência física, como Feliz Ano Velho, de Marcelo Rubens Paiva (1982), ou Minha Profissão é Andar, de João Carlos Pecci (1980), dão a dimensão dos efeitos que há na perda de um corpo anteriormente vivenciado como "normal", no que diz respeito ao seu funcionamento e aparência.

Essas observações iniciais visam delimitar o foco deste trabalho: o percurso de uma sexualidade que se viu tolhida de importantes partes e funções do corpo. Em termos mais específicos, esta pesquisa teve por objetivo investigar a sexualidade masculina na paraplegia adquirida. Na medida em que se entende a sexualidade como uma construção que não se reduz ao registro biológico, o referencial teórico adotado é o da Psicanálise, sem, no entanto, ater-se à ortodoxia de alguma escola. 
O relato deste trabalho foi organizado em quatro conjuntos: no primeiro, procurou-se aproximar os temas deficiência e sexualidade masculina; no segundo, focalizou-se o método de investigação utilizado; no terceiro, os resultados encontrados; no quarto, as conclusões do estudo.

\section{DEFICIÊNCIA E SEXUALIDADE MASCULINA}

Enfocar a sexualidade masculina a partir da deficiência não é um tema recorrente na literatura da Psicologia. A rigor, verifica-se que os trabalhos sobre o assunto são poucos e esses, de modo geral, tratam de aspectos específicos de determinado tipo de deficiência. Nas paraplegias adquiridas, a deficiência em foco neste trabalho, a ênfase tem recaído sobre a reabilitação da função sexual, a qual compreende os aspectos fisiológicos, tais como ereções, ejaculações, orgasmo, por exemplo.

De forma mais detalhada, o estudo da área permite constatar algumas evidências. A primeira caminha em direção às conclusões de Bruns (1998), que vê a sexualidade das pessoas com deficiência velada pelo silêncio. A segunda aponta para o universo representacional que cobre a sexualidade dessas pessoas.

Nesse último domínio, um relevante estudo é apresentado por Giami e D'Allonnes (1984). Pesquisando a representação de pais e professores a respeito da sexualidade de pessoas com deficiência mental, eles se depararam com dois tipos predominantes de atitudes: pais que a vêem como angelical e professores que a recobrem com a dimensão da monstruosidade. Se a sexualidade é de anjo, ela não existe; se ela é de monstro, é necessário escondê-la. Os autores escrevem:

O sistema de representação edificado pelos pais e pelos educadores em torno da sexualidade dos deficientes mentais funciona como um sistema de defesa coletivo para com a sexualidade compreendida como ameaçadora, tanto em sua dimensão "selvagem" e "bestial", como na dimensão "angelical". É o conjunto da organização psicossexual dos deficientes mentais (com todas as diferenciações possíveis quanto à natureza da deficiência) que é apreendido fundamentalmente como intolerável. (GIAMI; D’ALLONNES, 1984, p. 40)

Investigando a sexualidade de pessoas cegas, Bruns e Leal Filho (1996) analisaram anúncios classificados, que visavam o estabelecimento de correspondência e ou vínculo afetivo, publicados na Revista Brasileira para Cegos e no jornal Folha de São Paulo. Entre outras constatações, os pesquisadores se depararam com descrições nas quais as pessoas com deficiência visual expressavam uma supervalorização dos atributos visuais.

Se no primeiro estudo citado, o de Giami e D'Allonnes (1984), a sexualidade é adjetivada, de modo a ser negada, no segundo, o de Bruns e Leal Filho (1996), ela mostra que os indivíduos com deficiência visual lançam mão do que consideram ser um comportamento padrão quando se lida com as coisas do sexo. 
Em um artigo sobre sexualidade e deficiência, Mazin e Pinel (1984) apontam que a negação da sexualidade das pessoas com deficiência acontece da mesma forma que lhes são vedadas melhores condições de vida e o desenvolvimento de potencialidades não exploradas. Para esses autores, a origem da dificuldade dessas pessoas no desempenho dos papeis de gênero deve-se à introjeção excessivamente rígida de papéis sexuais.

Estudando o autoconceito e a postura frente à sexualidade em dez pessoas com deficiência física, Aloisi e Lipp (1988) constataram que os homens (cinco ao todo) se atribuíram um número maior de pontos positivos que as mulheres em um questionário que avaliava a visão que tinham de si e a que supunham que os outros tinham sobre eles. Dos sujeitos pesquisados, $71,4 \%$ indicaram que a maior dificuldade que encontravam para ter um relacionamento sexual era o constrangimento que sentiam em expor sua deficiência física. Destacando a importância dos papéis sociais tradicionais nos resultados, os autores afirmam: "As respostas parecem refletir muito mais os papéis sociais a que todos estão, geralmente, expostos, do que uma dicotomia "deficiência não-deficiência", desde que o defeito físico não pareceu estar determinando seu comportamento verbal.” (ALOISI; LIPP, 1988, p.138)

Num dos poucos artigos que encontramos em que a condição masculina é pensada tendo em vista o uso de cadeira de rodas, Melo (1986) observa que é no confronto com os papéis sociais atribuídos aos homens que se localizam as maiores dificuldades de ser homem e ter uma deficiência física. Vale a pena reproduzir a cena narrada, tanto pelo seu caráter patético, como pelo que ela elucida.

Uma família comum de classe média, como muitas outras, foi passar um fim de semana em um sítio. Na hora em que se preparavam para deitar, eis que surge, dentro da rústica casa em que se alojavam, um perigoso agressor: um rato. A mulher dá um sonoro alerta, corre com as crianças para fora da casa e de pronto convoca o marido para cumprir sua missão histórica de defender a família das ameaças externas. Rapidamente, como qualquer macho que se preze, o marido pega uma vassoura para esmagar o insólito inimigo. Tudo seria fácil e natural, se este protetor não fosse um deficiente físico em cadeira de rodas! Entretanto, neste caso, como matar o pequenino roedor, se a mesma mão que é necessária para segurar a vassoura também é necessária para deslocar a cadeira de rodas e perseguir o agressor? Depois de longa e difícil disputa, de muito pega e solta vassoura, de muito pega e solta a cadeira de rodas, e de inúmeras e frustradas tentativas, o marido aliviado pode exibir o pequeno roedor morto, como símbolo de sua masculinidade e do cumprimento de seu papel de forte $\mathrm{e}$ protetor da família - do macho. (MELO, 1986, p. 79)

Segundo Nolasco (2001b), a representação do universo masculino está em crise. "Tarzan", arquétipo do herói viril e lutador, já teria começado esse século decrépito e o gordo e derrotado "Homer Simpson" seria o protótipo do homem 
médio, o oposto da virilidade e sedução. Para o autor, os homens estão expostos a um tipo de morte: o fim da sua representação social. Em suas palavras: "A masculinidade como uma representação social entrou em decadência. Na transição para o indivíduo moderno, tudo aquilo que simboliza o mundo dos homens sucumbiu" (NOLASCO, 2001a, p.12).

Entre os muitos aspectos passíveis de abordagem a respeito da sexualidade dos homens com paraplegia, a ênfase tem recaído principalmente sobre a ereção e a ejaculação, no que está implicada a idéia de virilidade e fertilidade, como vimos. Essa leitura da sexualidade masculina fica evidenciada, por exemplo, no fato de ser uma causa aceitável para a anulação de compromissos matrimoniais a não consumação do coito, tanto por tribunais civis quanto católicos, como mostra o romance $O$ Belo Antônio, de Brancati (1987).

Maior (1988), empenhada em uma compreensão que vá além da fisiologia, contesta a idéia de que a ausência de sensibilidade nos genitais está associada à indiferença ao sexo. Ela argumenta com a possibilidade do cérebro poder atuar, independentemente da genitália, na gênese da experiência erótica e indica a satisfação que lesados raquimedulares relatam por despertarem o desejo e a satisfação em seus parceiros. Em suas palavras:

$\mathrm{Na}$ pessoa com lesão medular o impulso sexual está integralmente preservado; poderá permanecer oculto no desequilíbrio emocional subseqüente à lesão, porém todos os pacientes, dentro de poucas semanas ou meses, terão sua atenção voltada para o sexo (MAIOR, 1988, p.16)

Salimene (1995), que pesquisou a sexualidade dos paraplégicos e se deparou, como Faro (1991), com os estereótipos da masculinidade, afirma que as pessoas com paraplegia necessitam de ajuda na reconstrução de sua identidade sexual, apontando para a necessidade da elaboração de uma nova imagem corporal, recuperação da auto-estima e reconstituição da identidade sexual. Advogando a sexualidade dos paraplégicos a autora escreve:

Existe a idéia pré-concebida de que o corpo fisicamente limitado será também um corpo sexualmente limitado [...] o que ainda pensa o senso comum é, na verdade, que a manifestação da sexualidade, a obtenção do prazer, inexiste para os portadores de deficiências físicas: o preconceito como valor cultural cristaliza a idéia de que a pessoa portadora de deficiência é assexuada. (SALIMENE, 1995, p. 39)

Para a autora, a visão da sexualidade masculina como instrumento de dominação e poder prejudica de modo mais severo as pessoas com deficiência. Em defesa destas, ela argumenta que, se as limitações físicas e funcionais são inegáveis, deve-se compreender a sexualidade em sentido amplo, e que as emoções que marcam a existência dessas pessoas permanecem.

Focalizando a relação entre identidade sexual masculina de lesados medulares e identidade como um todo, Scherb (1998, p. 144) observa: 
Com relação à identidade sexual, sentem-se esvaziados dos atributos masculinos socialmente transmitidos, tais como iniciativa, força, produtividade, responsabilidade e potência. As alterações operadas no desempenho sexual tendem a se refletir na identidade como um todo.

Pode-se notar que os dois últimos trabalhos citados, Salimene (1995) e Scherb (1998), ambos realizados com lesionados medulares, mas com objetivos diversos, dialogam. Neles a sexualidade é marcada pela permanência, enquanto desejo, e pela perda de atributos que até então a constituíam. Algumas perdas são da ordem das identificações, outras da ordem das sensações.

Numa apreciação global dos estudos da área podemos supor a presença de duas perspectivas básicas para situar o homem com paraplegia e a sua sexualidade. A primeira carrega as marcas da representação tradicional de homem e masculinidade, com a sexualidade que the corresponde. A segunda abre caminho para um questionamento dessas representações dominantes.

\section{MÉTODo}

Este trabalho insere-se entre as pesquisas de abordagem qualitativa, do tipo Estudo de Caso, em que os dados analisados resultam de interações entre o investigador e seus sujeitos/depoentes. Investigou-se a história de vida de um homem com paraplegia adquirida, recolhida por meio de três entrevistas semi-estruturadas que resultaram em um estudo de caso. As entrevistas foram gravadas em áudio e transcritas pelo pesquisador.

A história de vida colhida foi a de um representante típico do problema que ora se estuda. Foram consideradas como características fundamentais do colaborador o fato de ser do sexo masculino, jovem/adulto e de ter adquirido a deficiência.

Ele foi abordado e convidado a participar da pesquisa dentro dos limites estabelecidos pelo que reza a Resolução 196/96 do Conselho Nacional de Saúde a respeito de pesquisas envolvendo seres humanos, assinando o termo de consentimento, do qual recebeu uma cópia. Nesse termo de consentimento consta o título da pesquisa, nome do pesquisador, número de registro profissional do mesmo e, em termos simples, as justificativas do trabalho e seu objetivo.

Nosso colaborador, apelidado de Juca neste estudo, é um homem que estava com 26 anos quando, em 2002, nos concedeu, em sua casa, as três entrevistas. Disse que viu seu corpo formar-se na lida, que bebeu de uma cultura de raízes sertanejas obediente aos ciclos da natureza e que foi vítima, aos 22 anos, em uma cidade grande em relação à sua, de um tiro que lhe atingiu a coluna vertebral. Esse tiro provocou uma lesão medular na altura da vértebra "T5", ao que tudo indica incompleta. O projétil ainda permanece em seu corpo e o tornou paraplégico. Tal evento ocorreu em uma atividade que historicamente praticara como divertimento, uma briga, que nesse caso específico resumiu-se a insultos verbais alusivos à masculinidade do oponente e que nem chegou às vias de fato, com golpes e murros. 
Logo após sofrer a lesão medular, revoltado com o seu estado de saúde e não aceitando ser ajudado por sua companheira - numa determinada situação, ser empurrado por ela na cadeira de rodas - rompeu a relação, que, depois de algum tempo, foi retomada. Atualmente, vive há dois anos uma relação estável com ela sem ter contraído um casamento formal, quer civil ou religioso. A lesão levou-o ao abandono de sua profissão de frentista de posto de gasolina e a se aposentar. Para complemento de renda, vende balas e chicletes em um cruzamento de avenida da cidade. A renda mensal do casal, sem contar o ganho com o comércio de confeitos, era em torno de R $\$ 500$ na ocasião das entrevistas.

As limitações percebidas por Juca se restringem a subir escadas, já que ele afirma conseguir fazer quase tudo e possuir um grande nível de autonomia, mesmo locomovendo-se em cadeira de rodas. Sua sensibilidade táctil está preservada da altura dos mamilos para cima e ele indica o surgimento de áreas mais sensíveis na barriga. Quanto à função sexual, relata ereções espontâneas (psicogênicas) e, o que é mais comum, estimuladas (reflexas). Entre um e dois anos após o acidente, Juca, pela primeira vez depois de lesionado, teve uma ejaculação, que foi percebida, de maneira não imediata, pela visão e pelo tato das mãos. Depois dessa vez, de forma não constante, consegue ejacular.

O procedimento de análise dos dados foi efetuado em praticamente todas as etapas do trabalho empírico - entrevistas, transcrição, digitação e leitura -, mas, sobretudo, quando relações entre diferentes trechos do material coletado, ou hipóteses interpretativas, ocorriam ao investigador e eram discutidas com o colaborador.

\section{Resultados}

Pensar a masculinidade de Juca implica considerar, de início, uma afirmação sua, a de que "Um homem, depois que ele nasce homem, é macho!", que implica uma concepção de que a questão de gênero é uma continuidade da natureza, já que macho, além de alusiva aos órgãos sexuais, como ele aprendeu a reconhecer em sua experiência rural, aponta a conotação de virilidade.

Sua história de vida vai aos poucos produzindo alterações nesse modo de pensar, principalmente depois da lesão medular. Até ela, sem se dar conta, Juca é um homem, como aprendeu a ser, em um processo constante de reafirmação, que em seu caso parece objetivar a ocupação de um espaço no universo masculino.

Nesse contexto, as brigas, nas quais ele se envolvia com outros homens, ocupavam um papel importante: "Bati, apanhei, foi bom [...] ninguém nunca só bate". Se esses fragmentos apontam os aspectos gozosos do brigar, as exigências sociais de bravura faziam parte desses atos: "Eu não levei desaforo para casa. Já briguei até com soldado da polícia por causa de um tapa na cara". Juca reconhece a valentia anterior à lesão medular. "Ah, eu antes do tiro, era meio 'galudim'. Eu acho que todo solteiro é, né?"

A força física o ajudava, tanto nos embates físicos como na comparação com seus oponentes. Ele podia sentir-se superior à maioria, ou equiparar-se aos melhores. "Para me bater mesmo, com vontade, tinham que ser de dois para cima. 
Uma pessoa sozinha podia ser forte e tudo que... me batia, mas não era assim aquela tunda, aquele coro". Além disso, sua condição física e masculina era, no contexto das brigas, um instrumento de dissuasão e que exigia respeito em todas as situações. "Eu não aceitava ninguém fazer deboche comigo, desfazer de mim. Você custa a ter as coisas e aí vem um e diz: você comprou esse trem velho? Esse trem ruim?".

Que as brigas foram uma constante na vida do jovem Juca, é um fato. Além disso, há em seu discurso evidências de que elas acompanhavam uma determinada forma de pensar. Desde a idéia de que todo solteiro é valente, até a noção das brigas como um instrumento presente em situações que envolvem a possibilidade de conquista das fêmeas. "Eu acho que se eu tivesse casado no tempo que eu andava, eu não implicava e tal, eu brigava em baile, esses trens assim".

Alguns elementos parecem constituintes da concepção de masculinidade que ele possuía antes da lesão medular, e se refletiam em seus atos, como a sua forma de brigar. "Podia apanhar do jeito que for, nunca veio na minha cabeça ah, vou pegar um revólver, vou buscar uma faca... não". Mesmo considerando as brigas como um dispositivo para colocar essas idéias à prova, o seu discurso delimita um espaço em que elas cabem, como inerentes à vida dos homens: "É gostoso você falar eu bati, apanhei, é bom. É ruim você falar: eu só bati. É mentira ninguém nunca só bate", mas recusa a ver-se definido por praticá-las. "Vamos corrigir. Eu brigava, mas eu não me punha como um brigão, de brigar toda hora, todo dia". Assim, ele estabelece uma diferenciação entre o que lhe parece ser um homem de bem, mas que "não afina" fugindo da briga, e outros, que fazem da contenda sua profissão de fé, e que, por isso, aproximam-se da marginalidade. Essa idéia de digno e respeitador permanecerá nas concepções de homem que ele sustentará depois da lesão medular.

Recordamos que para Juca o homem nasce macho, e que uma das características que ele atribui a esse homem é a brutalidade: "Os homens são muito brutos". Mesmo reconhecendo que essa afirmação não cobre todos os integrantes do gênero, já que considera que existem outros que são carinhosos, entre os quais se inclui: "eu sou da moda antiga". Na contramão, ele caracteriza o tipo que julga bruto: "Têm homens que só querem tirar a roupa e pronto. Não sabem fazer um carinho, não sabem tratar uma mulher".

A primeira ejaculação de Juca depois da lesão, além de seus outros significados possíveis, devolve-lhe um atributo que considera típico da masculinidade e que considerava perdido. "Depois que eu levei o tiro, a primeira vez que eu gozei para mim foi a mesma coisa que eu ter ido para o céu. Eu parei, olhei aquele trem escorrendo, peguei e falei, mas o que é isso?". É uma constatação de que o seu equipamento genital desempenhava todas as suas funções, o que lhe possibilita expressar o desejo de ser pai e acalentar o sonho de um filho.

Contudo, a idéia de virilidade, associada à de força, cria um problema para Juca após a lesão medular, na medida em que ele tenta sustentá-la apesar das perdas que teve em termos de funções. Sua relação afetiva com a namorada é a primeira vítima: 
Eu a carregava no colo, nos braços, eu andava com ela para todo lado sem nunca precisar dela; me senti, não sei se humilhado ou se é vergonhoso. Para mim naquele momento, em que ela estava me ajudando, doeu e a raiva veio à cabeça. Eu não aceitei ajuda dela. De amigo, mãe, um irmão, eu não importava.

Tal orientação gera sentimentos de menos valia: "parecia que eu estava sendo incapaz para ela, não sei te explicar", em que o que há de menos é a masculinidade tal qual ele a pensara até então. "Eu acho que todo homem tem seu lado masculino. O problema foi o pouco tempo, eu não conhecer, não saber nada. No começo eu fiquei revoltado".

Um novo posicionamento de Juca em relação à masculinidade fica evidente diante da sua atitude de aceitar a ajuda da namorada, quando ambos se propõem a construir uma casa: "Para fazer a casa, eu e ela, juntos, pagamos pedreiro, tudo o que tinha que pagar. Eu com minha aposentadoria, ela com o salário dela". E aceita que ela tome a dianteira e lidere a empreitada: "ela fez mais do que eu aqui. Qualquer coisinha ela corria atrás e dava os pulos dela". O coroamento dessa mudança ocorre com o acolhimento do sentimento de solidão na casa vazia e o reconhecimento da necessidade dela ao seu lado. "Eu fiquei aqui sozinho uma semana, depois fiz um trato com o pai dela, de que nos casaríamos em três meses, e ela veio morar comigo. Já faz dois anos, mas eu vou casar com ela".

Com essas mudanças que se operam no modo de Juca conceber os homens, estes passam a ser definidos por outros valores, distantes da valentia e imponência física. "Para mim, um homem tem que ser digno, ter respeito, respeitar todo o mundo, ser respeitado, não maltratar ninguém. Sei lá, um homem é um homem".

\section{Conclusões}

Apesar da idéia de masculinidade tradicional permear a mente de Juca, seu ato de duvidar dos que "só batem e nunca apanham", quando considerado como um exercício de masculinidade, indica que ele colocava sob suspeita tal idéia, em que predomina a gabolice dos feitos masculinos. É necessário lembrar que esse é o modo de pensar do Juca que já experimentou a vida e a masculinidade acompanhadas das seqüelas de uma lesão medular. Seu universo anterior a esse período remete ao mito do herói forte, valente e desbravador da natureza, como vimos pelos aportes de Nolasco (2001b). Recordemos que a briga que o vitimou pode ser considerada como uma de suas atividades de lazer, o que reforça a associação entre masculinidade e violência apontada por esse autor.

Se as brigas representavam um exercício de masculinidade, parece que se constituíam numa espécie de exibição de dimorfismo sexual, destinado às fêmeas, em quem os solteiros estavam interessados, e, além disso, uma apresentação ao público, no qual os lutadores veriam refletidos os seus atributos de força e valentia.

Para Juca, o homem nasce macho e o gênero parece ser uma dádiva da natureza, que se manifesta à cultura no momento do nascimento de uma criança. 
Tal concepção, provavelmente ligada à observação dos genitais no momento do nascimento de animais durante sua vivência rural, quando aplicada aos homens, determina não somente o sexo biológico como também o gênero. Isso tem por conseqüência uma rigidez na forma de pensar a sexualidade, em que a construção social e histórica do gênero não é considerada.

O primeiro gozo/ejaculação após a lesão, ainda que notado como diferente, já que Juca utiliza-se da visão e do tato preservado nas mãos para certificar-se dele, sugere a restauração da masculinidade que parecia abalada, ainda que o gozo ocorra como uma constatação e não como uma sensação. A virilidade é atestada pela ereção, penetração e ejaculação.

O temor de não responder mais assim e não ser homem desse jeito foi o que o fez sentir-se humilhado e envergonhado diante da ajuda da parceira empurrando sua cadeira de rodas. Essa dificuldade de Juca diante da parceira indica mais que uma questão de orgulho, um sentimento de inadequação masculina. Sua exigência era apresentar-se como o parceiro amoroso, de quem se podia esperar a força e a virilidade, implícitas nas idéias de homem que acalentava. A fragilidade em que se percebe precisa ser ocultada, na medida em que dista da sua idéia de homem e que imagina ser a mesma de sua namorada.

Para permitir que a mulher tome a dianteira, Juca precisa aceitar que possui algumas capacidades limitadas. Esse novo posicionamento parece ocorrer quando admite conversar com a namorada de quem havia se afastado e, depois de reatada a relação, concorda que ela assuma as rédeas das atividades necessárias à construção da casa.

A aceitação do afeto da companheira permite resignificar os gestos de ajuda dela, não como algo que humilha e envergonha, mas como uma demonstração de que ele é desejável como homem e parceiro sexual. Isso não só atenua a sua visão estereotipada de masculinidade, como também possibilita a renúncia a "ser o homem da casa", no sentido de tomar a dianteira nos empreendimentos do casal, já que a mulher, que ocupa esse lugar, o reconhece como homem para si. Juca pode então ser outro homem, sem demonstrações físicas (força, brigas, bagunças) de virilidade, mas digno, respeitador, que reconhece o outro, para quem a sexualidade permanece importante, mas inclui o afeto pela mulher que ama. Ele é homem porque uma mulher o coloca nesse lugar.

Com tal posicionamento, Juca demonstra desprendimento em relação à imagem usual de masculinidade, na qual foi formado, e, com isso, consegue reestruturar sua vida, mesmo com suas atuais limitações físicas. Vale recordar que o apego rígido às representações usuais de masculinidade tem se constituído num problema central nessa área, aspecto esse mencionado em vários estudos citados nesta pesquisa (ALOISI; LIPP, 1988; FARO, 1991; MAZIN; PINEL, 1984; MELO, 1986; SALIMENE, 1995).

Em que pese a fragilização da representação tradicional de masculinidade e a sua substituição por outra que beira o cômico, como é a tese de Nolasco (2001b), $\mathrm{o}$ fato é que o homem comum penosamente tenta assemelhar-se à representação 
daquele que subjugava a natureza, tendo direito por isso às fêmeas e ao prestígio. Contudo, Hércules, Tarzan, e mesmo os heróis ficcionais marcados pelas dores do homem contemporâneo, como o Batman e o Homem-Aranha, são da ordem dos supra-humanos. Também os ícones modernos, como os atletas e os artistas, ganham no tratamento que recebem da publicidade um caráter quase messiânico. Porém, para o homem comum é uma impossibilidade atingir essas representações e a busca das mesmas tende a acarretar formas de arremedo grotesco. Assim, podemos dizer que todo homem é um desviante em relação à representação tradicional da masculinidade.

Por fim, de acordo com os achados desta pesquisa qualitativa, com a ocorrência da paraplegia adquirida, Juca deparou-se com a representação tradicional de masculinidade e percebeu que o confronto entre a sua vida sexual anterior e a posterior à lesão medular depunha contra ele, o que o levou a se reposicionar e a valorizar a sua experiência singular, reinventando a sua sexualidade e masculinidade.

\section{REFERÊNCIAS}

ALOISI, H.; LIPP, M. Autoconceito e sexualidade na opinião de pessoas portadoras de defeito físico. Estudos de Psicologia, Campinas, SP, v. 5, n. 2, p. 127-141, ago./ dez. 1988.

BRANCATI, V. O Belo Antônio. Rio de Janeiro: Nova Fronteira, 1987.

BRUNS, M. A. T. Educacion sexual y deficiência visual: el diálogo del silêncio por el silêncio del diálogo. Separata de: Revista de Psicologia, Lima, v. 16, n. 1, p. 84-101, 1998.

BRUNS, M. A. T.; LEAL FILHO, B. F. Sexualidade, deficiência visual e os meios de comunicação. Revista Integração, Brasília, DF, v. 7, n. 17, p. 27-30, 1996.

CASALIS, M. E. P. Sexualidade no paciente paraplégico. In: D’ANCONA, C. A. L.; NETTO Jr.; N. R. (Ed.). Aplicações clínicas da urodinâmica. São Paulo: Atheneu, 1995. p. 295-310.

COLUCCI, C. Tiros lideram causa de lesão medular em São Paulo. Folha de São Paulo, São Paulo, p. C4, 26 maio 2003.

FARO, A. C. M. Estudo das alterações da função sexual em homens paraplégicos. 1991. Dissertação (Mestrado)-Escola de Enfermagem, Universidade de São Paulo, São Paulo, 1991.

GIAMI, A.; D'ALLONNES, C. R. O anjo e a fera: as representações da sexualidade dos deficientes mentais pelos pais e educadores. In: D’ÁVILA NETO, M. I. (Org.). A negação da deficiência: a instituição da diversidade. Rio de Janeiro: Achiamé / Socius, 1984. p. 29-41. 
Luiz Carlos Avelino da Silva e Paulo Albertini

MAIOR, I. M. M. L. Reabilitação sexual do paraplégico e tetraplégico. Rio de Janeiro: Revinter, 1988.

MAZIN, R.; PINEL, A. Sexualidade e deficiência. Ciência Médica, [S.1.], v. 2, n. 5, p. 16-23, jun. 1984.

MELO, C. P. Reflexão sobre o homem e a deficiência física. In: COSTA, R. P. Macho masculino homem. São Paulo: L\&PM, 1986. p.79-83.

MOOR, L. Elementos de psicologia médica. Barcelona: Toray, 1973.

NOLASCO, S. A violência é masculina. Isto É, São Paulo, n. 1662, p. 9-13, $2001 \mathrm{a}$. Entrevista concedida a Eliane Lobato em 5 ago. 2001.

. De Tarzan a Homer Simpson: banalização e violência masculina em sociedades contemporâneas ocidentais. Rio de Janeiro: Rocco, 2001b.

PAIVA, M. R. Feliz ano velho. São Paulo: Brasiliense, 1982.

PECCI, J. C. Minha profissão é andar. São Paul: Summus, 1980.

SALIMENE, A. C. M. Sexo: o caminho para a reabilitação. São Paulo: Cortez, 1995.

SCHERB, E. Deficiência fisica adquirida por lesão medular traumática: estudo da auto-imagem. 1998. Dissertação (Mestrado)-Instituto de Psicologia, Universidade de São Paulo, São Paulo, 1998.

VASH, C. Enfrentando a deficiência: a manifestação, a psicologia, a reabilitação. São Paulo: Pioneira: EDUSP, 1988.

Recebido em: maio/ 2006

Aceito em: outubro/ 2006 